\title{
A compreensão é um dos níveis de leitura: experimentações e sensações - itinerários de literatura e clínica
}

Alexandre de Oliveira Henz ${ }^{1}$

Danilo Alves da Cruz ${ }^{2}$

Ana Beatriz Franceschini ${ }^{3}$

Aurélio Keiji Miyaura ${ }^{4}$

Fernanda Braz Tobias de Aguiar ${ }^{5}$

Gabryell Tavares de Barbosa ${ }^{6}$ Maurício Hideo Inamine ${ }^{7}$

Natasha Porto Scavone Joukhadar ${ }^{8}$

Rafaela Camargo Baldo ${ }^{9}$

Rui Teixeira Lima Junior ${ }^{10}$

Golem é uma palavra que aparece uma só vez na Bíblia, no salmo 139:16, e que quer dizer: sem forma, o informe. Golem (Scholen, 1994, p.57-59) é um ser feito de argila e, conta a cabala, que os judeus poloneses o fabricaram depois de certas orações e dias de jejum, na forma de um homem de barro. Sobre este homúnculo, pronunciaram o sheruramphuras miraculoso - o nome de Deus - e este ser adquiriu vida. Embora não pudesse falar, ele compreendia suficientemente o que lhe ordenavam e executava trabalhos domésticos. $O$ Golem não deveria jamais sair da casa e, em sua fronte, estava escrito: Emeth - (E.M.E.T.H) que em hebraico quer dizer: Verdade. Ele crescia rapidamente a ponto de se tornar maior do que todos os que viviam na casa, mesmo tendo sido fabricado bem pequeno. Então, eles apagavam a primeira letra do nome inscrito em sua testa, e ele se tornava Meth (M.E.T.H), que quer dizer: morto. De EMETH (verdade) para METH (morto). Então, ele caía e se transformava novamente em argila. Diz a lenda que, certa vez, um homem deixou crescer em demasia o seu golem. Ele ficou tão grande que já não era mais possível alcançar a sua fronte. Então, o homem ordenou que o golem lhe tirasse as botas. Quando o golem curvou-se, ele pode enfim atingir-lhe a testa, mas tão logo retirou a primeira letra de emeth, todo aquele peso de argila caiu sobre ele e o soterrou.

As experimentações do projeto Literatura e Clínica lembram, às vezes, por sua precariedade, essa versão de um golem sempre inconcluso. A literatura e os encontros, na sua fragilidade e força, com suas verdades, num processo sempre de reconstrução a partir do informe, dos destroços anteriores, também precisam, para sustentar-se, de muita engenhosidade, acaso e, repetidas vezes, de uma boa dose de torcida desejante. Aquela que nós podemos oferecer a partir dos dispositivos de escuta, leitura, conversação, passando todos eles pelas modalidades mais diversificadas de encontro. Mas nada está dado de antemão, nenhuma verdade, e o que se dá em cada encontro jamais está garantido. Apagar muitas vezes o e de emeth pode ser pouco, e, frequentemente, dez vezes é ainda insuficiente para problematizar nossas verdades domésticas e domesticadas.

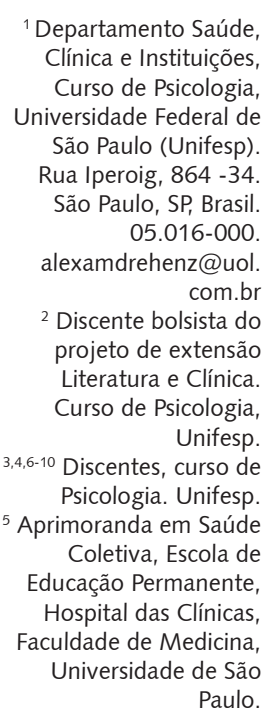


Com esses apontamentos iniciais, nos aproximamos um pouco da espessura das questões desse projeto de extensão, para apresentar algumas experimentações, na verdade uma série de vinhetas e notas um pouco ziguezagueantes. Ele teve início em outubro de 2006 e já passou por duas etapas. A primeira foi mais focalizada no público interno da Universidade Federal de São Paulo - Campus Baixada Santista. Participavam das rodas de leitura e discussão, quase que exclusivamente professores, estudantes e técnicos. Os encontros tinham periodicidade quinzenal e consistiam na leitura coletiva e discussão de contos, poesias, fragmentos literários de autores como: D.H. Lawrence, Borges, Virginia Woolf, Kafka, Oscar Wilde, entre outros. Questões como: política, morte, vida, diferença, o inusitado e as "saúdes frágeis", que marcam certas literaturas, ofereceram possibilidades para distintas sensações e percepções na vizinhança do trabalho da clínica. Essa etapa do projeto Literatura e Clínica durou três anos e foi encerrada em meados de 2009.

O projeto agenciou encontros entre estudantes de vários cursos de graduação na área da saúde (Educação Física, Nutrição, Fisioterapia, Terapia Ocupacional e Psicologia), os diversos grupos populacionais de Santos, e contos, poesias, hai-kais e fragmentos literários. A finalidade foi instigar sensibilidades, sensações, encontros permitindo a constituição de novas faixas de escuta.

A partir de agosto de 2009, continuamos com os encontros abertos a frequentadores do campus, quando as atividades eram realizadas na Unifesp, e a novidade, no segundo semestre de 2009, foi a realização de encontros fora da universidade, em diversos estabelecimentos da cidade de Santos. Nesse momento o projeto ganhou um caráter itinerante, sempre com cinco a seis estudantes, um professor e o coletivo do local. Ocorreram dois encontros em cada estabelecimento, com duração de aproximadamente duas horas, onde obras ou trechos de obras literárias foram lidas, seguidos de conversações. A ideia não foi fazer crítica literária ou falar sobre a literatura, mas permitirse a experimentação e o encontro com as obras e os usuários dos estabelecimentos públicos e equipamentos de saúde de Santos.

Os primeiros dois encontros ocorreram em uma instituição que atende pessoas com deficiência visual. Lá trabalhamos com dois grupos distintos e propusemos a leitura de um pequeno conto de Franz Kafka - aliás, nesse momento do projeto, propusemos várias experimentações com contos deste autor que nos pareciam captar certos movimentos subterrâneos do século passado e deste. O primeiro conto foi "Diante da lei" (Kafka, 1999a), que disponibilizamos tanto em braile, para aqueles com perda total de visão, quanto em tamanho ampliado, para os com visão subnormal; os dois formatos foram preparados pela própria instituição. Na roda de leitura, percebemos que todos ficaram à espreita de cada palavra; a impressão que tivemos era de que seus ouvidos pinçavam os sons e as palavras lidas.

Na conversa, várias perspectivas surgiram em torno do conto, e foi atribuído, ao personagem de Kafka, o homem do campo, diversos rótulos identitários: o inculto, o pobre, o brasileiro, o cego, todas as figuras clichês de um imaginário social apoiado na aspiração à lei e que por ela espera até o final. Várias situações do cotidiano dos cegos foram relatadas nesse momento.

Após cada encontro, várias questões eram discutidas na reunião de articulação do projeto de extensão; uma delas foi a de que não seria interessante romantizar ou idealizar a cegueira. A experimentação com alguns cegos havia sido potente, alguns deles, chegando à velhice, aprenderam, inclusive, a considerar a cegueira como uma saída das meras evidências para uma espécie de clareza maior e insubmissão. Um deles contou, por exemplo, que quando uma funcionária do banco não queria permitir que fechasse a conta, já que por ser cego teria de fazê-lo somente por telefone, ele não aceitou a argumentação burocrática e, indo adiante da lei, encerrou a conta. Os contrastes mais óbvios nos assaltavam o pensamento; ocorria que, muitas vezes, nós é que estamos ofuscados pelo visível, submissos às leis ou tomados de onipotência.

No segundo encontro, um dos cegos praticamente monopolizou a discussão com uma apologia a Deus e à esperança do homem diante da lei, o que nos pareceu uma espécie de reação ao conto, menos pelas suas convicções religiosas e mais pela dificuldade de coletivizar a experiência. A cegueira na velhice, assim como qualquer ponto de estrangulamento vital, não era uma garantia de tornar-se sábio, mas para alguns, em algumas situações, podia auxiliar na suspensão da visão ordinária e seus referenciais, criando a possibilidade de um vazio germinador. 
Outros dois encontros ocorreram na praia de Santos, na biblioteca do Posto 6. A divulgação ocorreu através da agenda cultural da Secretaria Municipal de Cultura, o que atraiu um público formado por funcionários da biblioteca, professores, escritores e estudantes da Unifesp. Desta vez, utilizamos o conto "Chacais e Árabes" (Kafka, 1999b); e, após a leitura, a discussão se ramificou e espraiou para diversas questões - em ressonância ou não com o conto - e emergiram temas como a subordinação ao poder e a servidão voluntária. Os chacais são uma espécie de matilha intensa, que não para de entranhar-se no deserto seguindo linhas de fuga. Apresentam bem o problema da "limpeza" e, nisso, algo da ordem da política pareceu afetar as discussões do grupo - o politicamente correto, as novas leis e os microrregramentos do cotidiano foram alguns desses assuntos; elementos do plano sensível quase imperceptíveis. Em todos os encontros, nos interessava muito esse campo das sensações. Para os nossos hábitos naturalizados parece que pensar é, inevitavelmente, raciocinar e compreender. Nesse dia tivemos a experiência de que o pensamento e a afetação são encontros: de alguém com um chacal, um deserto, um som, uma política, uma cor e, eventualmente, uma conversa. Em vários momentos, nas rodas de leitura, o que preponderava eram as regiões de sensibilidade. Éramos afetados por alguma coisa, independentemente de uma compreensão racional na leitura do escrito de Kafka. A compreensão era somente um dos vários níveis de leitura (Deleuze, 2008). Por exemplo, para apreciar um quadro de Cézanne, Gauguin ou outro grande artista, não é preciso conhecê-lo profundamente. O conhecimento profundo de um conto de Kafka, assim como dos termos técnicos da pintura, pode ajudar, mas também há sensações intensas, fortes e violentas na ignorância total da pintura. É claro que alguém pode ficar abalado, afetado por um conto, fragmento literário ou um quadro, e não saber nada a seu respeito. Podemos ficar muito tocados por uma música ou com uma determinada obra musical sem saber uma palavra de música clássica. Isso, de certo modo, marcou o encontro do Posto 6, e, mais do que tudo, pôs em análise o dispositivo que tínhamos produzido, nos levando a essas questões e suas múltiplas possibilidades.

São em momentos como esses que podemos acompanhar pequenos exercícios de invenção, de paciência, de lentidão, de gratuidade, de angústia aceita, de dúvida, enfim, exercícios de literatura e clínica.

Esses foram os encontros iniciais, e alguns outros já ocorreram em situações diversas, com a presença destes mesmos participantes em configurações grupais diferentes. Atualmente, o trabalho ocorre transversalmente, em colaboração com o estágio de quarto ano do curso de psicologia, com outro projeto de extensão ligado a redes sociais, e um módulo de segundo ano de trabalho em saúde que envolve os seis cursos do campus. Sabemos que, a seu modo, este projeto é quase imperceptível, um fio tênue e potente em sua pequena circunscrição, que sinaliza efeitos e problematiza fôrmas e formatações, impacta a superexcitação acadêmica, a aceleração, e as coisas em sua suposta naturalidade.

Essas foram algumas notas, um percurso rápido por algumas experimentações que esses encontros puderam propor. Retomando a formulação inicial deste escrito, a figura do golem convém a este projeto na medida de sua instabilidade na instauração de verdades. Finalizaremos esse breve percurso de alguns itinerários de literatura e clínica com um fragmento do livro "Revolução eletrônica" de William Burroughs, cujas ressonâncias com o projeto Literatura e Clínica são as que tentam deixar em desuso verdades definitivas e cansativas dicotomias, usos imperativos de artigos definidos (o, a) e relações de exclusão (ou isso... ou aquilo). Diz o trecho:

O É da Identidade. Tu és animal. Tu és um corpo. Ora sejas tu o que fores não és um 'animal', não és um 'corpo', porque isso são rótulos verbais. O É da identidade compreende sempre a implicação disso e de mais nada e compreende também [...] uma condição permanente. Permanecer assim. Toda a apelação pressupõe o É da identidade. Este conceito é desnecessário numa língua hieroglífica, como o antigo egípcio, e é de fato frequentemente omitido. Não é preciso dizer que o sol É do céu. Sol no céu basta. Podemos facilmente omitir o verbo qualquer que seja a língua, o que fizeram os discípulos do conde Korzybski eliminando o verbo ser em inglês [...]. Os artigos definidos O A OS AS (the). "O" compreende a implicação de um só e único: O Deus, O universo, O caminho, O certo, O errado. Se existe um outro, então 
ESSE universo, ESSE caminho não são mais O universo, O caminho. O artigo definido será eliminado e substituído pelo artigo indefinido UM UMA. Todo conceito de OU/OU. Certo ou errado, físico ou mental, verdadeiro ou falso, todo o conceito de OU será [...] substituído pela justaposição, por E. (Burroughs, s/d, p. 87-9)

\section{Colaboradores}

Todos os autores participaram, igualmente, de todas as etapas de elaboração do artigo.

\section{Referências}

BURROUGHS, W. A revolução eletrônica. Trad. Maria Leonor Telles e José Augusto Mourão. Lisboa: Vega, s/d.

DELEUZE, G. N de Neurologia. In: DELEUZE, G. L'Abecedaire de Gilles Deleuze. Entrevista concedida à Claire PARNET, realizada em 1988 e transmitida em série televisiva a partir de novembro de 1995, pela TV-ARTE, Paris. 2008. Disponível em http://www. oestrangeiro.net/esquizoanalise/67-o-abecedario-de-gilles-deleuze. Acesso em: 19 out. 2011.

KAFKA, F. Chacais e árabes. In: KAFKA, F. Um médico rural. São Paulo: Companhia das Letras, 1999a. p.30-5.

Diante da lei. In: KAFKA, F. Um médico rural. São Paulo: Companhia das Letras, $\overline{1999 b}$. p.27-9.

SCHOLEN, G. O. Golem, Benjamin, Buber e outros justos: judaica I. São Paulo:

Perspectiva, 1994. 